\title{
Article \\ Effect of Kaempferol and Its Glycoside Derivatives on Antioxidant Status of HL-60 Cells Treated with Etoposide
}

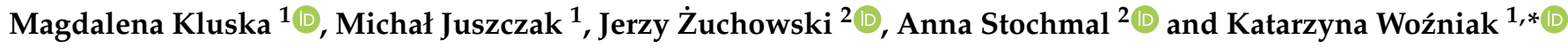 \\ 1 Department of Molecular Genetics, Faculty of Biology and Environmental Protection, University of Lodz, \\ 90-236 Lodz, Poland; magdalena.kluska@edu.uni.lodz.pl (M.K.); michal.juszczak@edu.uni.lodz.pl (M.J.) \\ 2 Department of Biochemistry and Crop Quality, Institute of Soil Science and Plant Cultivation, State Research \\ Institute, 24-100 Pulawy, Poland; jzuchowski@iung.pulawy.pl (J.Ż.); asf@iung.pulawy.pl (A.S.) \\ * Correspondence: katarzyna.wozniak@biol.uni.lodz.pl; Tel.: +48-42-635-47-76; Fax: +48-42-635-44-84
}

Citation: Kluska, M.; Juszczak, M.; Żuchowski, J.; Stochmal, A.; Woźniak K. Effect of Kaempferol and Its Glycoside Derivatives on Antioxidant Status of HL-60 Cells Treated with Etoposide. Molecules 2022, 27, 333. https://doi.org/10.3390/ molecules27020333

Academic Editors: Vassya Bankova and Milena Popova

Received: 23 November 2021

Accepted: 3 January 2022

Published: 6 January 2022

Publisher's Note: MDPI stays neutral with regard to jurisdictional claims in published maps and institutional affiliations.

Copyright: (C) 2022 by the authors. Licensee MDPI, Basel, Switzerland. This article is an open access article distributed under the terms and conditions of the Creative Commons Attribution (CC BY) license (https:// creativecommons.org/licenses/by/ $4.0 /)$.

\begin{abstract}
Kaempferol is a well-known antioxidant found in many plants and plant-based foods. In plants, kaempferol is present mainly in the form of glycoside derivatives. In this work, we focused on determining the effect of kaempferol and its glycoside derivatives on the expression level of genes related to the reduction of oxidative stress-NFE2L2, NQO1, SOD1, SOD2, and HO-1; the enzymatic activity of superoxide dismutases; and the level of glutathione. We used HL-60 acute promyelocytic leukemia cells, which were incubated with the anticancer drug etoposide and kaempferol or one of its three glycoside derivatives isolated from the aerial parts of Lens culinaris Medik.- kaempferol 3-O-[(6$O$ - $E$-caffeoyl)- $\beta$-D-glucopyranosyl-( $(\rightarrow 2)]-\beta$-D-galactopyranoside-7-O- $\beta$-D-glucuropyranoside (P2), kaempferol 3-O-[(6-O-E- $p$-coumaroyl)- $\beta$-D-glucopyranosyl- $(1 \rightarrow 2)]-\beta$-D-galactopyranoside-7- $O-\beta$ D-glucuropyranoside (P5), and kaempferol 3-O-[(6-O-E-feruloyl)- $\beta$-D-glucopyranosyl-(1 $\rightarrow 2)]-\beta$-Dgalactopyranoside-7-O- $\beta$-D-glucuropyranoside (P7). We showed that none of the tested compounds affected NFE2L2 gene expression. Co-incubation with etoposide $(1 \mu \mathrm{M})$ and kaempferol $(10$ and $50 \mu \mathrm{g} / \mathrm{mL})$ leads to an increase in the expression of the HO-1 $(9.49$ and 9.33 -fold at $10 \mu \mathrm{g} / \mathrm{mL}$ and $50 \mu \mathrm{g} / \mathrm{mL}$, respectively), SOD1 (1.68-fold at $10 \mu \mathrm{g} / \mathrm{mL})$, SOD2 (1.72-fold at 10-50 $\mu \mathrm{g} / \mathrm{mL}$ ), and NQO1 (1.84-fold at $50 \mu \mathrm{g} / \mathrm{mL})$ genes in comparison to cells treated only with etoposide. The effect of kaempferol derivatives on gene expression differs depending on the derivative. All tested polyphenols increased the SOD activity in cells co-incubated with etoposide. We observed that the co-incubation of HL-60 cells with etoposide and kaempferol or derivative P7 increases the level of total glutathione in these cells. Taken together, our observations suggest that the antioxidant activity of kaempferol is related to the activation of antioxidant genes and proteins. Moreover, we observed that glycoside derivatives can have a different effect on the antioxidant cellular systems than kaempferol.
\end{abstract}

Keywords: kaempferol; kaempferol derivatives; etoposide; oxidative stress; gene expression; SOD activity; glutathione

\section{Introduction}

Reactive oxygen species (ROS) play an important role in the pathogenesis of many diseases, including cancer, neurodegenerative, the respiratory system, and gastrointestinal tract diseases [1]. A high level of ROS in normal cells contributes to the damage of DNA, lipids, and proteins and then to mutagenesis and transformation [2]. On the other hand, cancer cells are characterized by elevated levels of ROS caused by altered metabolism and increased energy demand [1]. ROS play a role in different stages of cancer development, such as transformation, invasion, and metastasis [3]. Glutathione ( $\gamma$-glutamyl-cysteinylglycine) is a primary low-molecular-weight thiol that plays a key role in antioxidant defense; nutrient metabolism; and the regulation of cellular processes, such as DNA and protein synthesis, gene expression, or apoptosis [4]. Under physiological conditions within the cell, 
glutathione exists mainly ( $>99 \%)$ in the thiol-reduced form (GSH), but some is present as GSSG (glutathione disulfide), as well as a variety of thioether, mercaptide, or other thioester forms (glutathione S-conjugates). Increased levels of GSH have been associated with chemotherapeutic resistance, e.g., for platinum-containing compounds, alkylating agents (such as melphalan), anthracyclines, doxorubicin, or arsenic, and to ionizing radiation resistance [5]. It was proposed that a decrease in the glutathione level was associated with the sensitizing of leukemia cells to chemotherapy in combination with polyphenols [6]. Treatments with quercetin, apigenin, emodin, rhein, and cis-stilbene decrease the GSH level in lymphoid leukemia cell lines (Jurkat and CCRF-CEM) and leads to enhancement of the anticancer activity of topoisomerase II poisons etoposide or doxorubicin. Moreover, in myeloid cell lines (THP-1 and KG1a), quercetin and apigenin reduce the level of glutathione and enhance the apoptotic effect of the drugs [7].

Nuclear factor erythroid 2-like 2 (NFE2L2 or NRF-2) is a key cytoprotective molecule responsible for regulating the expression of antioxidant proteins, including heme oxygenase-1 (HO-1), NAD(P)H:quinone oxidoreductase 1 (NQO1), the catalytic subunit of glutamatecysteine ligase (GCLC), and multi-drug resistance genes family [8-11]. It is sequestered in the cytoplasm by Kelch-like ECH-associated protein 1 (Keap1). During oxidative stress, NFE2L2 is released from Keap1 and then translocated into the nucleus. There, along with other transcription factors, NFE2L2 activates the transcription of genes containing an antioxidant response element (ARE) [12]. Unfortunately, NFE2L2 activation triggers antioxidant pathways that protect cancer cells against the effects of chemotherapeutic agents [13] Moreover, the NFE2L2 gene is overexpressed in many types of human tumors, such as breast cancer [14] or gastric cancer [15], which contributes to chemoresistance. On the other hand, NFE2L2 silencing increases the sensitivity of cancer cells to chemotherapeutic drugs [16]. NFE2L2 is constitutively active in human acute myeloid leukemia (AML) cells, and these cells possess greater constitutive nuclear levels of NFE2L2 than normal control CD34+ cells [17].

$\mathrm{HO}-1$ catalyzes heme degradation to equimolar amounts of carbon monoxide (CO), iron ions, and biliverdin, which is rapidly converted to bilirubin through the action of biliverdin reductase (BVR). Although the main mechanism of HO-1 activity is related to heme metabolism, $\mathrm{HO}-1$ also plays a role in the cellular response to oxidative stress. HO-1 is upregulated by many different factors, not only by heme but also by nitric oxide, heavy metals, growth factors, cytokines, or modified lipids. Moreover, the HO-1 protein is involved in several other cellular processes, such as cell proliferation, angiogenesis and metastasis, apoptosis, and inflammation [9]. The $\mathrm{NAD}(\mathrm{P}) \mathrm{H}$ quinone oxidoreductase 1 gene (NQO1) is a downstream gene of NFE2L2-ARE signaling. The NQO1 enzyme is one of the most important enzymes responsible for antioxidant defense. Its primary function is to catalyze the two-electron reduction of endogenous and exogenous quinones to hydroquinones, removing the electrophilic quinones and bypassing semiquinone radical and ROS generation via redox cycling reactions. Moreover, NQO1 can reduce superoxide in tissues with low levels of superoxide dismutases (SOD) [10]. It was shown that the expression level of the NQO1 gene may be associated with the proliferation of many tumor cells, including brain cancer and leukemia [18-20]. NQO1 controls cell proliferation and apoptosis by stabilizing p53 [21].

Superoxide dismutases (SOD) are one of the most important antioxidative enzymes, which convert superoxide radicals into hydrogen peroxide and molecular oxygen. This enzyme occurs in three isoforms: SOD1 $(\mathrm{Cu} / \mathrm{Zn} \mathrm{SOD})$ is located in the intermembrane space of the mitochondria, the nucleus, and the cytosol; SOD2 (Mn-SOD) is present in the mitochondrial matrix; and SOD3 (Ec SOD) is a secreted form expressed in the lungs, kidneys, and adipose tissues to prevent oxidative tissue damage. SOD1 is the major intracellular form of SOD, accounting for $\sim 80 \%$ of the total SOD protein, and it acts as a scavenger of $\mathrm{O}_{2}{ }^{-}$generated by NADPH oxidase (NOX), xanthine oxidase, and cytochrome P450. Moreover, SOD1 scavenges $\mathrm{O}_{2}{ }^{-}$in the mitochondrial intermembrane space during electron transport [22]. SOD1 is overexpressed in many types of cancer, including non-small 
cell lung cancer (NSCLC) [23], breast cancer [24], or nasopharyngeal carcinoma [25]. In addition to $\mathrm{O}_{2}{ }^{-}$scavenging, SOD1 and SOD2 are actively involved in modulating diverse cellular processes. $\mathrm{H}_{2} \mathrm{O}_{2}$, the dismutating product of $\mathrm{O}_{2}{ }^{-}$by SOD, can act as a second messenger to regulate cellular growth and metabolic processes [22]. It is suggested that SOD can be a novel promising target in cancer therapy [26].

Kaempferol [3,5,7-trihydroxy-2-(4-hydroxyphenyl)-4H-1-benzopyran-4-one] is a natural flavonoid widely present in tea, grapes, berries, and cruciferous vegetables. It has antioxidant, anticancer, and anti-inflammatory properties [27]. In our previous papers, we analyzed the impact of kaempferol and its glycoside derivatives isolated from Lens culinaris Medik. on HL-60 cells and PBMCs (peripheral blood mononuclear cells) treated with etoposide $[28,29]$. We demonstrated that kaempferol glycosides reduced the DNA damage induced by etoposide in PBMCs, but they did not have an impact on the DNA damage in HL-60 leukemic cells [28]. Previously, we have also shown that kaempferol increases the cytotoxic effect of etoposide in HL-60 cells [29]. On the other hand, kaempferol reduced the level of free radicals generated by etoposide. However, some of the kaempferol derivatives increased the level of free radicals induced by this drug [29]. Due to the fact that the antioxidant status of cancer cells may be of key importance for the effectiveness of anticancer therapy, in the present work, we decided to investigate the effect of kaempferol and its glycoside derivatives on the expression of the NFE2L2 gene and its downstream genes: HO-1, NQO1, SOD1, and SOD2 in HL-60 cells treated with etoposide. Here, we used kaempferol glycoside derivatives isolated from aerial parts of Lens Culinaris Medik. the same that we used in our last paper (Figure 1B-D [29]). Moreover, here, we determined the activity of SOD and the level of total glutathione content in HL-60 cells treated with etoposide and tested polyphenols.

\section{Materials and Methods}

\subsection{Reagents}

3,4',5,7-Tetrahydroxyflavone (kaempferol) (K0133), 4'-demethylepipodophyllotoxin 9-(4,6-O-ethylidene- $\beta$-D-glucopyranoside) (etoposide) (E1383), dimethyl sulfoxide (DMSO), and 5-Sulfosalicylic acid dihydrate (247006) were purchased from Sigma-Aldrich (St. Louis, MO, USA). Kaempferol was dissolved in DMSO and stored at $-20^{\circ} \mathrm{C}$. Etoposide was dissolved in methanol. The SOD Assay Kit WST (Lot. SJ972) was purchased from Dojindo Molecular Technologies, Inc. (Kumamoto, Japan). The Glutathione Colorimetric Detection Kit (catalog number: EIAGSHC) was purchased from Thermo Fisher Scientific (Waltham, MA, USA).

\subsection{Kaempferol Glycosides from the Aerial Parts of Lentil}

Kaempferol glycosides: kaempferol 3-O-[(6-O-E-caffeoyl)- $\beta$-D-glucopyranosyl-(1 $\rightarrow 2)]-$ $\beta$-D-galactopyranoside-7-O- $\beta$-D-glucuropyranoside (P2), kaempferol 3-O-[(6-O-E- $p$-coumaroyl)$\beta$-D-glucopyranosyl-( $(1 \rightarrow 2)]-\beta$-D-galactopyranoside-7-O- $\beta$-D-glucuropyranoside (P5), and kaempferol 3-O-[(6-O-E-feruloyl)- $\beta$-D-glucopyranosyl-( $1 \rightarrow 2)]-\beta$-D-galactopyranoside-7-O$\beta$-D-glucuropyranoside (P7) were isolated from the aerial parts of Lens culinaris Medik., according to the procedure described by Żuchowski et al. (2014) [30]. All isolated kaempferol glycosides were dissolved in 50\% DMSO and stored at $-20{ }^{\circ} \mathrm{C}$ [29].

\subsection{Cell Preparation and Treatment}

The HL-60 (human promyelocytic leukemia) cell line was obtained from the American Type Culture Collection (ATCC) (Manassas, VA, USA). The cells were cultured in flasks at $37^{\circ} \mathrm{C}$ in $5 \% \mathrm{CO}_{2}$ atmosphere in Iscove's Modified Dulbecco's Medium (IMDM), 2-mM L-glutamine, and 25-mM HEPES (Lonza, Basel, Switzerland) with 15\% inactivated fetal bovine serum (FBS) and penicillin/streptomycin solution $(100 \mathrm{U} / \mathrm{mL}$ and $100 \mu \mathrm{g} / \mathrm{mL}$, respectively).

In all experiments, the HL-60 cells were seeded in the culture medium and then incubated at $37^{\circ} \mathrm{C}$ with different concentrations $(10-50 \mu \mathrm{g} / \mathrm{mL})$ of kaempferol: kaempferol 3-O- 
[(6-O-E-caffeoyl)- $\beta$-D-glucopyranosyl-( $1 \rightarrow 2)]-\beta$-D-galactopyranoside-7-O- $\beta$-D-glucuropyranoside (P2), kaempferol 3-O-[(6-O-E- $p$-coumaroyl)- $\beta$-D-glucopyranosyl-( $1 \rightarrow 2)]-\beta$-D-galactopyranoside7-O- $\beta$-D-glucuropyranoside (P5), and kaempferol 3-O-[(6-O-E-feruloyl)- $\beta$-D-glucopyranosyl$(1 \rightarrow 2)]-\beta$-D-galactopyranoside-7-O- $\beta$-D-glucuropyranoside $(\mathrm{P} 7)$. The cells were also treated with etoposide $(1 \mu \mathrm{M})$. The final concentration of DMSO and methanol in the samples did not exceed $0.5 \%$ [29].

\subsection{Gene Expression Analysis}

To analyze the gene expression, the cells $\left(0.5 \times 10^{5}\right)$ were seeded in 6-well plates and incubated with $1-\mu \mathrm{M}$ etoposide and/or $10-50-\mu \mathrm{g} / \mathrm{mL}$ kaempferol, P2, P5, and P7 at $37^{\circ} \mathrm{C}$ for $24 \mathrm{~h}$. Afterwards, the cells were collected, and the total RNA from each sample was extracted using the Universal RNA Purification Kit (EurX, Gdansk, Poland), according to the manufacturer's instructions. Reverse transcription and real-time PCR reactions were performed using the SensiFAST ${ }^{\mathrm{TM}}$ Probe No-ROX One-Step Kit (Bioline, London, UK) on the CFX96 C1000 real-time system (Bio-Rad, Hercules, CA, USA). The relative expression was evaluated using the TaqMan gene expression assay for HO-1: Hs00157965_m1, NFE2L2: Hs00975961_m1, NQO1: Hs00168547_m1, SOD1: Hs00533490_m1, SOD2: Hs00167309_m1, and GAPDH: Hs02786624_m1 (Thermo Fisher Scientific, Waltham, MA, USA). The GAPDH gene was utilized as a reference gene. Each assay was performed in quadruplicate. The relative gene expression was calculated as the fold change according to the control sample based on the double-delta Ct method.

\subsection{Superoxide Dismutase (SOD) Activity}

To measure the activity of SOD, the cells were seeded in 6-well plates and incubated with 1- $\mu \mathrm{M}$ etoposide and/or 10-50- $\mu \mathrm{g} / \mathrm{mL}$ kaempferol, P2, P5, and P7 at $37^{\circ} \mathrm{C}$ for $24 \mathrm{~h}$. Then, the cells were collected, and the cell lysates were prepared. The cells $\left(1 \times 10^{6}\right)$ were centrifuged at $250 \times g$ for $10 \mathrm{~min}$ at $4{ }^{\circ} \mathrm{C}$. Next, the supernatant was discarded, and the cell pellet was resuspended in ice-cold PBS. Then, the cells were centrifuged again at $250 \times g$ for $10 \mathrm{~min}$ at $4{ }^{\circ} \mathrm{C}$. The supernatant was discarded, and the cells were resuspended in $0.5 \mathrm{~mL}$ of PBS and sonicated under ice for $30 \mathrm{~s}$ using the 4710 Series Ultrasonic Homogenizer (Cole-Parmer Instrument Co., Chicago, IL, USA). After that, samples were centrifuged at $1500 \times \mathrm{g}$ for $10 \mathrm{~min}$ at $4{ }^{\circ} \mathrm{C}$. The supernatant was collected, transferred into 96-well plates, and the SOD activity was measured. To determine the SOD activity, the SOD Assay Kit WST was used according to the manufacturer's procedures (Dojindo Molecular Technologies, Inc., Kumamoto, Japan). The plates were incubated for $20 \mathrm{~min}$ at $37^{\circ} \mathrm{C}$, and the absorbance at $450 \mathrm{~nm}$ was measured using a Synergy HT microplate reader (Biotek, Bad Friedrichshall, Germany). Each assay was performed in triplicate. Then, the SOD activity was calculated using the following Equation (1):

SOD activity $($ inhibition rate $\%)=\left[\left(\mathrm{A}_{\text {blank1 }}-\mathrm{A}_{\text {blank } 3}\right)-\left(\mathrm{A}_{\text {sample }}-\mathrm{A}_{\text {blank2 } 2}\right)\right] /\left(\mathrm{A}_{\text {blank1 }}-\mathrm{A}_{\text {blank } 3}\right) \times 100$

A-absorbance

The data were normalized to the negative control, which was assigned as $100 \%$ of the SOD activity.

\subsection{Determination of Total Glutathione Content}

The total glutathione (GSH + GSSG) content was determined using the Glutathione Colorimetric Detection Kit (Thermo Fisher Scientific, Waltham, MA, USA). HL-60 cells were incubated with 1- $\mu \mathrm{M}$ etoposide and/or 10-50- $\mu \mathrm{g} / \mathrm{mL}$ kaempferol, P2, P5, and P7 in culture flasks for $24 \mathrm{~h}$. After the incubation, cells were collected and centrifuged at $800 \times g$ for $10 \mathrm{~min}$ at $4{ }^{\circ} \mathrm{C}$. Then, the cells were washed by centrifugation in ice-cold PBS at $800 \times g$ for $10 \mathrm{~min}$ at $4{ }^{\circ} \mathrm{C}$. The $\left(4 \times 10^{6}\right)$ cells were resuspended in ice-cold $5 \% 5$-sulfosalicylic acid solution and sonicated under ice for $30 \mathrm{~s}$ using the 4710 Series Ultrasonic Homogenizer (Cole-Parmer Instrument Co., Chicago, IL, USA). Next, the homogenate was incubated for $10 \mathrm{~min}$ at $4{ }^{\circ} \mathrm{C}$ and centrifuged at $17,000 \times \mathrm{g}$ for $10 \mathrm{~min}$ at $4{ }^{\circ} \mathrm{C}$. The supernatant was 
collected, transferred into 96-well plates, and assayed for glutathione, according to the manufacturer's instructions. After 5 min of incubation at room temperature, the absorbance was measured at $405 \mathrm{~nm}$ using a Synergy HT microplate reader (Biotek, Bad Friedrichshall, Germany). Each assay was performed in triplicate. The data were normalized to the negative control, which was assigned as 100\% of the GSH level (GSH + GSSG).

\subsection{Statistical Analysis}

Expression of the genes was calculated based on the double-delta $\mathrm{Ct}$ method. The data were presented as the mean \pm SD from 4 independent experiments. In the case of SOD activity and the glutathione level, the data were presented as the mean \pm SD from 3 independent experiments. Statistical differences were determined by one-way ANOVA with the post hoc Tukey's multiple comparison test and by the Student's two-tailed $t$-test. Statistics were performed using GraphPad Prism 5 (GraphPad Software Inc., La Jolla, CA, USA). The differences were considered to be statistically significant when the $p$-value was less than 0.05 .

\section{Results}

\subsection{Antioxidant Defense Gene Expression}

We determined the expression of antioxidant defense genes: NFE2L2, HO-1, NQO1, SOD1, and SOD2 in HL-60 cells incubated with a combination of etoposide and kaempferol or its glycoside derivatives (Figure 1). We did not observe any impact of etoposide; kaempferol; or its glycoside derivatives (P2, P5, and P7) on the expression level of the NFE2L2 gene. Among the examined genes, etoposide did not change the expression profiles of NQO1, SOD1, and SOD2. We noticed that etoposide increased the expression of the HO-1 gene 4.9-fold $(p<0.001)$ at a $1-\mu \mathrm{M}$ concentration. Kaempferol also induced a 1.4-fold and 2.5-fold increase of HO-1 gene expression at the $10-\mu \mathrm{g} / \mathrm{mL}$ and $50-\mu \mathrm{g} / \mathrm{mL}$ concentrations ( $p<0.05$ and $p<0.001$, respectively). Moreover, the co-treatment with kaempferol significantly increased the expression of HO-1 in comparison to cells incubated only with etoposide, from 4.9-fold to 9.5-fold and 9.3-fold at the $10-\mu \mathrm{g} / \mathrm{mL}$ and $50-\mu \mathrm{g} / \mathrm{mL}$ concentrations, respectively $(p<0.001)$. We did not observe any changes in the $\mathrm{HO}-1$ gene expression after incubation with all kaempferol glycoside derivatives. Interestingly, we observed an increase in the $\mathrm{HO}-1$ expression in cells co-treated with etoposide and kaempferol derivatives. The greatest increase was recorded in the case of $50-\mu \mathrm{g} / \mathrm{mL}$ P5, from 4.9-fold to 10-fold compared to etoposide (E) $(p<0.001)$. A less significant increase occurred also in the case of co-incubation with derivatives P2 at $50 \mu \mathrm{g} / \mathrm{mL}, \mathrm{P} 5$ at $10 \mu \mathrm{g} / \mathrm{mL}$, and P7 at both concentrations.

We observed that incubation with kaempferol increased the NQO1 gene expression in both used concentrations ( $p<0.01$ and $p<0.001$, respectively) (Figure 1). Moreover, all three tested kaempferol glycosides, at the concentration of $50 \mu \mathrm{g} / \mathrm{mL}$, also increased the NQO1 expression. The co-treatment of cells with kaempferol or its glycosides and etoposide basically did not affect the expression of the NQO1 gene. We observed only a slight increase $(p<0.05)$ of NQO1 expression in cells co-treated with etoposide and 50- $\mu \mathrm{g} / \mathrm{mL}$ kaempferol and $50-\mu \mathrm{g} / \mathrm{mL}$ P7.

The next genes we examined were superoxide dismutases SOD1 and SOD2. We noticed that $50-\mu \mathrm{g} / \mathrm{mL}$ kaempferol slightly increased the levels of both the SOD1 and SOD2 genes (1.4-fold and 1.5-fold, respectively) $(p<0.01)$ (Figure 1). In the case of P2, we observed only a slight increase in the SOD1 expression in lower concentrations $(p<0.05)$. The glycoside derivative of kaempferol P5 increased SOD1 and SOD2 only in the $10-\mu \mathrm{g} / \mathrm{mL}$ concentration ( $p<0.001$ and $p<0.05$, respectively), while P7 increased the expression of both SOD1 and SOD2 in a higher concentration ( $p<0.001$ and $p<0.05$, respectively). We observed the increase of SOD1 expression in cells co-incubated with etoposide and kaempferol $(10 \mu \mathrm{g} / \mathrm{mL})$, P2 (10-50 $\mu \mathrm{g} / \mathrm{mL})$, and P7 (10-50 $\mathrm{g} / \mathrm{mL})$ glycoside derivatives compared to drug-only treated cells. We also noted that the co-treatment of cells with etoposide and kaempferol significantly increased the expression of the SOD2 gene $(p<0.05$ 
and $p<0.01)$. The increase in SOD2 expression also occurs in the case of cells co-incubated with etoposide and all three tested kaempferol derivatives at the concentration of $50 \mu \mathrm{g} / \mathrm{mL}$ (1.9-fold, 1.6-fold, and 1.4-fold, respectively).
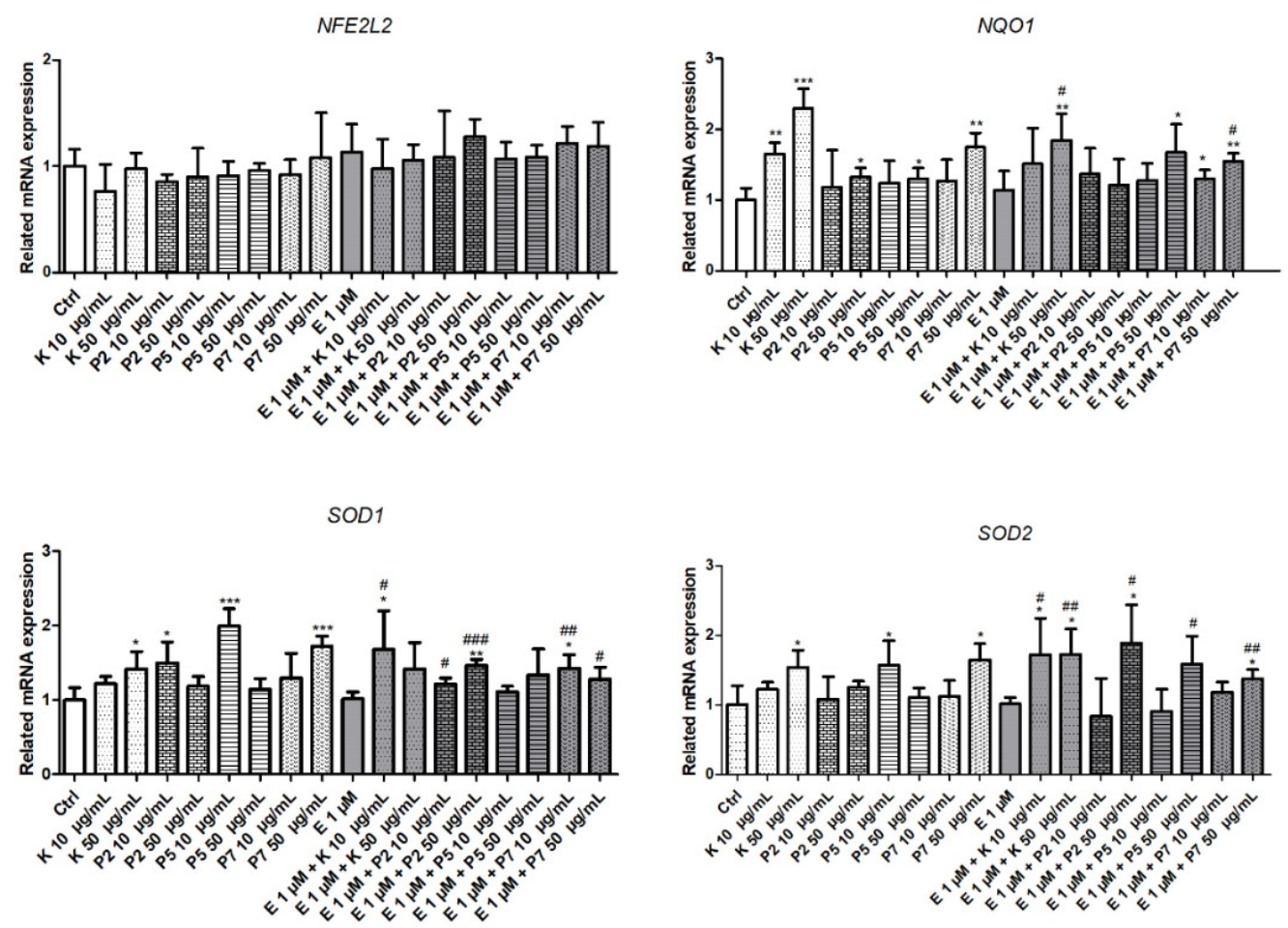

HO-

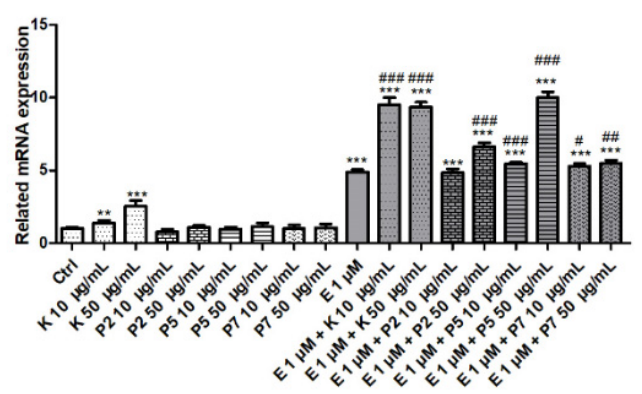

Figure 1. Relative expression of the NFE2L2, NQO1, SOD1, SOD2, and HO-1 genes in HL-60 cells incubated for $24 \mathrm{~h}$ at $37^{\circ} \mathrm{C}$ with 10-50- $\mu \mathrm{g} / \mathrm{mL}$ kaempferol (K), P2, P5, P7, and/or 1- $\mu \mathrm{M}$ etoposide (E). The figure shows the mean results $\pm \mathrm{SD}, n=4 ;^{*} p<0.05,{ }^{* *} p<0.01$, and ${ }^{* * *} p<0.001$ vs. control (Ctrl); \# $p<0.05$, \#\# $p<0.01$, and \#\#\# $p<0.001$ vs. etoposide (E).

A summary of the results of the antioxidant defense genes expression after incubation of the HL-60 cells with etoposide and polyphenols is presented in Table S1.

\subsection{SOD Activity}

The next step was to examine the enzymatic activity of SOD. For this purpose, we performed the determination of the enzymatic activity using the WST-1 solution. Firstly, we noticed that $1-\mu \mathrm{M}$ etoposide induced a slight increase in the SOD enzyme activity $(p<0.05)$ (Figure 2). As in the case of gene expression, we did not observe any changes in the cells incubated with $10-\mu \mathrm{g} / \mathrm{mL}$ kaempferol in the enzymatic activity test. Moreover, we noticed that $50-\mu \mathrm{g} / \mathrm{mL}$ kaempferol increased the SOD activity to $147 \%$ in comparison to the control cells $(p<0.001)$ (Figure 2). Similar activity to kaempferol was shown by its two glycoside derivatives P2 and P5. They increased the enzymatic activity of SOD in HL-60 cells at both concentrations used. On the other hand, the P7 compound did not affect the 
SOD activity. Interestingly, we observed that all the tested polyphenols increased the SOD activity in cells incubated with etoposide. In the case of kaempferol and derivative P7, the increase in SOD activity in the cells incubated simultaneously with etoposide occurred at both tested concentrations $(p<0.001)$. In contrast, P2 and P7 only increased the activity of SOD in drug-treated cells at a lower concentration $(p<0.001)$.
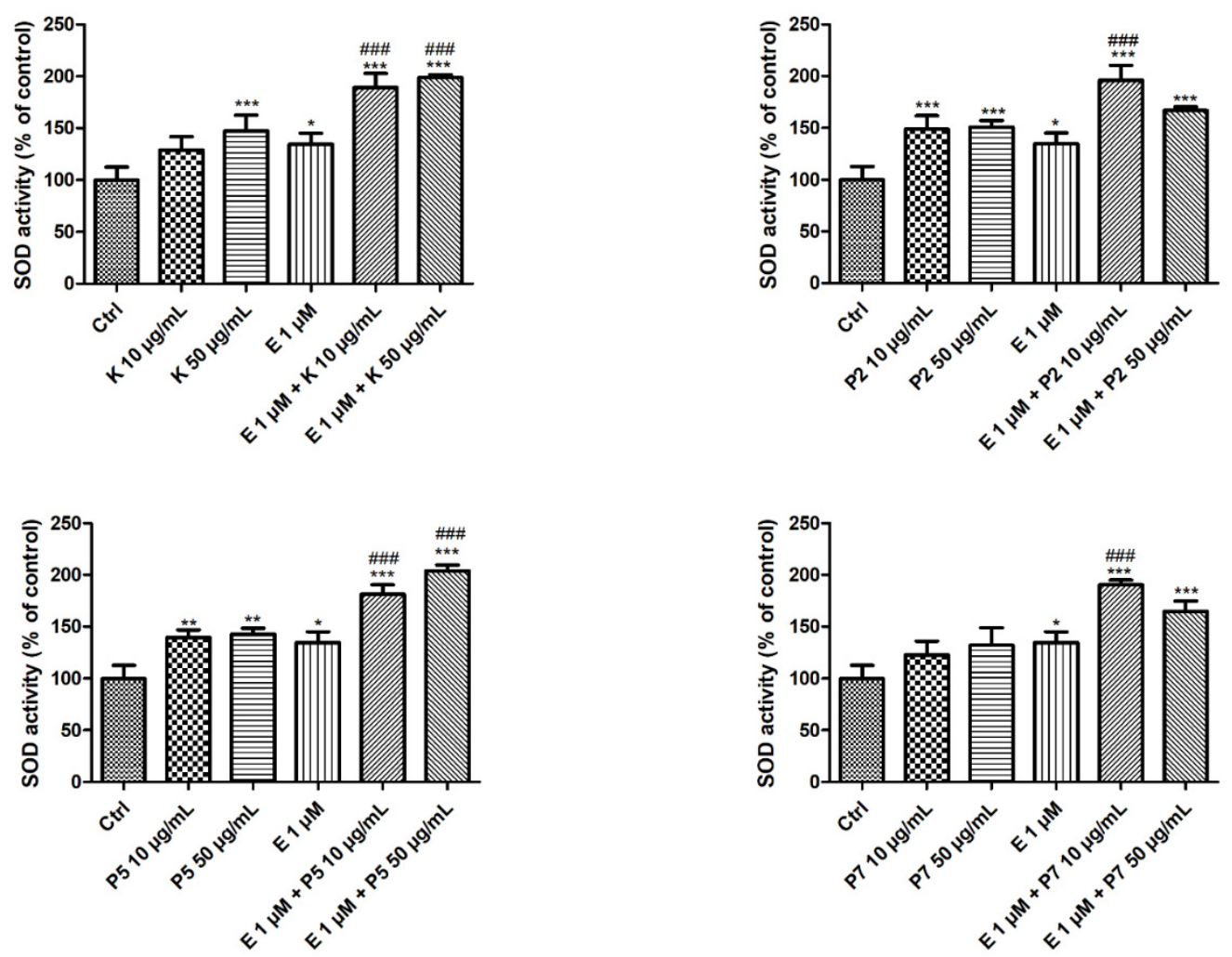

Figure 2. Superoxide dismutase activity in HL-60 cells incubated for $24 \mathrm{~h}$ at $37^{\circ} \mathrm{C}$ with $10-50-\mu \mathrm{g} / \mathrm{mL}$ kaempferol (K), P2, P5, P7, and/or 1- $\mu \mathrm{M}$ etoposide (E). The figure shows the mean results $\pm \mathrm{SD}$, $n=3{ }^{*} p<0.05,{ }^{* *} p<0.01$, and ${ }^{* * *} p<0.001$ vs. control (Ctrl); \#\#\# $p<0.001$ vs. etoposide $€$. Data were normalized to the negative control, which was assigned as $100 \%$ of the SOD activity.

\subsection{Total Glutathione Level}

We also determined the level of total intracellular glutathione using the colorimetric kit, which was designed to measure the glutathione (GSH) and oxidized glutathione (GSSG) content. Firstly, we noticed that the treatment of HL-60 cells for $24 \mathrm{~h}$ with 1- $\mu \mathrm{M}$ etoposide increased the level of total intracellular glutathione (Figure 3). Furthermore, both kaempferol and its glycoside derivatives did not affect the level of glutathione in HL-60 cells. However, we noticed that the co-incubation of cells with $1-\mu \mathrm{M}$ etoposide and kaempferol at the concentration of $50 \mu \mathrm{g} / \mathrm{mL}$ or derivative P7 at the concentration of $10 \mu \mathrm{g} / \mathrm{mL}$ increased the level of total glutathione in HL-60 cells in comparison to cells treated only with etoposide $(p<0.05$ and $p<0.001$, respectively). Additionally, both derivatives P2 and P5 had no effect on the glutathione level in cells incubated with etoposide (Figure 3). 

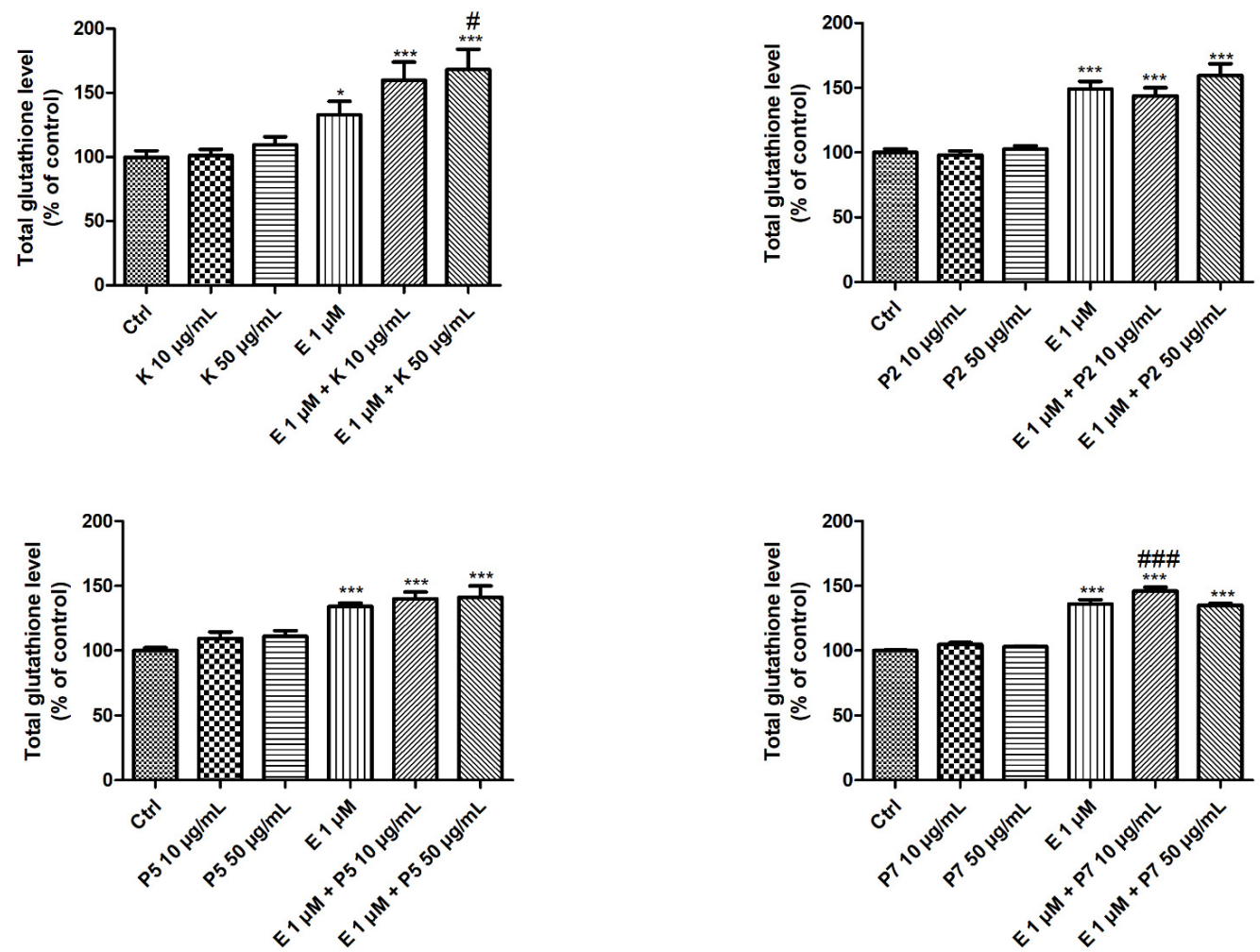

Figure 3. The total glutathione level in HL-60 cells incubated for $24 \mathrm{~h}$ at $37^{\circ} \mathrm{C}$ with $10-50-\mu \mathrm{g} / \mathrm{mL}$ kaempferol (K), P2, P5, P7, and/or 1- $\mu \mathrm{M}$ etoposide (E). The figure shows the mean results $\pm \mathrm{SD}, n=3$; ${ }^{*} p<0.05$, and ${ }^{* * *} p<0.001$ vs. control (Ctrl); $\# p<0.05$, and \#\#\# $p<0.001$ vs. etoposide (E). Data were normalized to the negative control, which was assigned as $100 \%$ of the glutathione level.

\section{Discussion}

The use of anticancer therapy based on chemotherapeutic agents is associated with the occurrence of side effects caused by the damage of normal cells, such as cardiotoxicity, nephrotoxicity, or leukemia. Polyphenols can protect normal cells from the harmful effects of oxidative stress induced by oxidants, including anticancer drugs. In this paper, we investigated the effect of kaempferol and its glycosides on the etoposide activity in HL-60 cells. Many studies have shown that kaempferol or its derivatives have a beneficial effect on normal cells. For example, a 24-h pre-incubation of human normal lung epithelial (L132) and liver (L02) cells with kaempferol and 3-O-methyl quercetin isolated from S. anacardium significantly reduced $\mathrm{H}_{2} \mathrm{O}_{2}$-induced stress and increased the expression of NFE2L2, p-p38, catalase, and superoxide dismutase-2 [31]. Flavonoids isolated from Petasites japonicus, which included, among others, kaempferol-3-O-(6"-acetyl)- $\beta$-D-glucoside and kaempferol$3-\mathrm{O}-\beta$-D-glucoside, activated the NRF-2 and HO-1 genes [32]. The activation of these pathways protected human dermal fibroblasts (HDF) and human epidermal keratinocyte cells (HEKC) against UVB radiation. Kaempferol protected the auditory cells of mice HEI-OC1 (House Ear Institute-Organ of Corti 1) from apoptosis induced by cisplatin. Its protective effect was based on inducing the expression of the HO-1 gene, increasing the cellular level of GSH, and the expression of $\gamma$-glutamate-cysteine ligase (GCL) [33]. Studies conducted on Balb/C mice have revealed that kaempferol improves cisplatin-induced nephrotoxicity [34]. The ameliorating effect of kaempferol was due to a reduction of oxidative stress, inflammation, and apoptosis via inhibiting the MAPK and NF- $\mathrm{kB}$ cascade and upregulation of the NRF-2/HO-1 levels. Moreover, it was shown that kaempferol enhanced the gene expression of thioredoxin reductase 1 (TXNR1) and thioredoxin (TXN) in normal human keratinocytes. Kaempferol and quercetin also increased the activity of thioredoxin reductase in these cells [35]. 
Mutations and/or upregulation of the NFE2L2 gene are observed in many human tumors and are associated with the resistance of cells to chemotherapy [13]. Somatic mutations in the coding region of NFE2L2 occur especially in patients with a history of smoking or suffering from squamous cell carcinoma and contribute to poor treatment prognosis [36]. NFE2L2 overexpression is associated with a higher frequency of gene mutation and instability-dependent drug resistance in AML patients. In vitro studies have shown that NFE2L2 overexpression protected the AML cells from apoptosis induced by cytarabine. Moreover, this overexpression inhibited MutS Homolog 2 (MSH2) protein expression, which caused a DNA mismatch repair deficiency and induced gene instabilitydependent drug resistance in AML [37]. The knockdown of the NFE2L2 gene in AML cell lines THP1 and U937 sensitized them to the daunorubicin and arsenic trioxide treatment by reducing the reactive oxygen scavenging capacity and downregulation of the target antioxidant genes. Additionally, treatment with brusatol is a pharmacological inhibitor of NFE2L2 and improved the sensitivity of AML cell lines to daunorubicin, arsenic trioxide, and cytarabine [38]. The combination of compounds that inhibit the expression of NFE2L2 with classic anticancer drugs may be a promising approach in the treatment of AML. AML is the most common type of leukemia among adults. The development of the disease is associated with the occurrence of chromosomal abnormalities that lead to the abnormal differentiation of hematopoietic stem cells and accumulation of abnormal blasts in the bone marrow [39]. AML is characterized by a refractory nature and poor prognosis; therefore, the treatment of this disease remains demanding. On the other hand, NFE2L2 controls the basal and induced expression of an array of antioxidant response element-dependent genes. By this way, it is involved in the protection of the body against cancer, but at the same time, it is overexpressed in different tumors, thus resulting in a pro-survival phenotype that favors tumor growth and resistance to oxidants and oncotherapy [40].

Many substances of plant origin, such as polyphenols, can modulate the expression of the NFE2L2 gene and could be used with chemotherapy to increase the therapeutic effect by sensitizing cells to anticancer drugs. The combination of quercetin and vitamin $C$ decreased the expression of NFE2L2 in both the mRNA and protein levels in the MDA-MB 231, MCF-7, A549, and MDA-MB 468 breast cancer cell lines [41]. In our study, we did not observe any changes in NFE2L2 gene expression in HL-60 cells treated with etoposide, kaempferol, and its glycosides or with the combination of these compounds (Figure 1). However, we noticed the upregulation of the NFE2L2 downstream genes NQO1, HO-1, SOD1, and SOD2 (Figure 1). In NSCLC lung cancer cells, treatment with $25-\mu \mathrm{M}$ kaempferol inhibited the NFE2L2 signaling pathway by reduction of both the NFE2L2 mRNA and protein levels [42]. Moreover, incubation with kaempferol did not change the level of NF- $\mathrm{kB}$ p65 and phospho NF-KB p65 in NSCLC cells. This study also revealed that kaempferol after $24 \mathrm{~h}$ of treatment reduced the expression of the NQO1, HO-1, GST, and AKR1C1 genes, which were dependent on NFE2L2. On the other hand, an extract from graviola leaves-rich in kaempferol-rutinoside-increased the expression of the NFE2L2 gene in HepG2 liver cancer cells but did not affect the expression of the HO-1 gene [43].

Many studies have indicated the important role of SOD in the pathogenesis and progression of cancer and the possibility of using the inhibition of its expression in therapy. The elevated activity of SOD1 is associated with NSCLC cell proliferation, migration, and invasion. The inhibition of SOD1 expression leads to the promotion of apoptosis and cell cycle arrest in these cells [23]. The knockdown of SOD1 in nasopharyngeal carcinoma cells reduced its growth and induced apoptosis [25]. SOD1 regulates cell death and differentiation in myeloid leukemia cell lines K562, MEG-01, TF-1, and HEL [44]. Additionally, the inhibition or silencing of SOD1 increased the cell death induced by PMA (phorbol 12-myristate 13-acetate). We observed that kaempferol and its derivatives increased the expression of the SOD1 and SOD2 genes (Figure 1) and elevated the activity of SOD in HL-60 cells (Figure 2). Zhao and co-workers showed that kaempferol at the concentration of $10 \mu \mathrm{g} / \mathrm{mL}$ increased the SOD2 activity in the human colorectal cancer cell line (Caco-2) [45]. Kaempferol at concentrations from 5 to $25 \mu \mathrm{M}$ increased the SOD 
activity in 3T3-L1 mouse fibroblast cells [46]. In this paper, we showed that kaempferol and its three tested glycoside derivatives increased the expression of the SOD1 and SOD2 genes and the activity of SOD in HL-60 cells co-incubated with etoposide (Figures 1 and 2). On the other hand, it also seems possible that kaempferol can stimulate enzyme activity through epigenetic mechanisms, including miRNAs [47]. This is probably why we showed an increase in SOD activity in the case of P5 at a concentration of $50 \mu \mathrm{g} / \mathrm{mL}$ (Figure 2), in which we did not observe expression of the SOD1 and SOD2 genes (Figure 1).

Additionally, other polyphenols can act synergistically with chemotherapeutics by modulating SOD activity. Apigenin inhibited SOD activity in human cervical epithelial carcinoma cells (HeLa) but did not alter the SOD protein level [48]. This inhibition of SOD activity contributed to the increase in the ROS level in the cells and sensitized them to paclitaxel-induced apoptosis. A combination of fluorouracil (5-FU) and natural polymethoxyflavonecastin led to an increase in apoptosis in the mouse leukemia cell line (WEHI-3) [49]. Moreover, this effect was associated with an increase in caspase-3, caspase-8, and caspase- 9 activity. The combined treatment also enhanced the expression of $\mathrm{Cu} / \mathrm{Zn}$ SOD and inhibited the activity of catalase.

Studies conducted on the HL-60 cell line cytarabine (Ara-C)-resistant sub-line HL-60R and on samples collected from patients suffering from AML indicate that an increased level of HO-1 gene expression is associated with resistance to chemotherapy [50]. Another study revealed that patients with AML had an overexpression of $\mathrm{HO}-1$ at both the gene and protein levels [51]. Research by Lin and colleagues indicated also that HO-1 suppressed the apoptosis of the HL-60 and U937 AML cell lines through activating the JNK/c-JUN signaling pathway. Moreover, the silencing of $\mathrm{HO}-1$ in the mouse xenograft model prolonged their survival [51]. On the other hand, it has been shown that cultured leukemic cell lines, such as HL-60, U937, and K562, are characterized by a low expression of the HO-1 gene [52]. In our conditions, kaempferol, in contrast to its glycoside derivatives, increased the expression of the HO-1 gene in HL-60 cells (Figure 1). Moreover, we observed that a co-treatment of the cells with all the tested polyphenols and etoposide increased the expression level of the HO-1 gene (Figure 1). Treatment with kaempferol also increased the HO-1 gene expression and the HO-1 protein level in the rat adrenal pheochromocytoma cell line (PC12) [53].

Here, we showed that kaempferol alone and in combination with etoposide significantly increases the expression of the NQO1 gene. Studies carried out on chronic myeloid leukemia K562 cells have shown that NQO1 knockdown promoted DNA synthesis and cell growth [20]. In addition, Xiao and colleagues tested the samples of peripheral blood or bone marrow specimens obtained from patients suffering from chronic myeloid leukemia and showed that the frequency of loss-of-function mutations of the NQO1 gene was higher than that in healthy individuals. The increased expression of NQO1 was also associated with the suppression of HL-60 cell proliferation [19]. Limonin, which is a secondary metabolite belonging to the tetracyclic triterpenoids, improved the activity of NQO1 in HL-60 cells and promoted apoptosis [54]. In our previous work, we demonstrated that a co-treatment of HL-60 cells with etoposide and kaempferol led to a decrease of cell viability measured by the resazurin reduction test [29]. Probably, the increase in cytotoxicity that we observed previously could be related to the increased expression of the NQO1 gene in HL-60 cells. All three tested kaempferol derivatives did not influence the cytotoxic effect of etoposide on HL-60 cells [29]. This is in line with the results describing NQO1 gene expression in cells co-treated with kaempferol derivatives and etoposide (Figure 1). P2 and P5 did not change the level of this gene in comparison to the cells incubated only with etoposide (Figure 1). We observed only a slight increase in NQO1 gene expression in the case of the P7 derivative at its highest concentration. Interestingly, mangiferin, which is a glucosylxanthone extracted from plants of the Anacardiaceae and Gentianaceae families, activated the NFE2L2-ARE pathway in HL-60 cells and increased NQO1 transcription, but a co-treatment of these cells with $50-\mu \mathrm{M}$ mangiferin and $4-500-\mu \mathrm{g} / \mathrm{mL}$ etoposide did not change the etoposide-induced cytotoxicity and apoptosis [55]. 
We observed that the incubation of HL-60 cells with 1- $\mu \mathrm{M}$ etoposide leads to an increase in the level of total intracellular glutathione (Figure 3). The increase in the level of total glutathione in cells incubated with the drug may be caused by the cellular response to the action of the oxidative stress-inducing factor, which is etoposide. On the other hand, it was shown that etoposide can act as both an antioxidant and a pro-oxidant in HL-60 cells [56]. The phenolic moiety of etoposide acts as an effective free radical scavenger, accounting for its antioxidant action, whereas the one-electron oxidation of etoposide by free radical scavenging and/or by myeloperoxidase (MPO) results in a phenoxyl radical with low reactivity toward lipids, but its high reactivity toward thiols is a determinant of its pro-oxidant effects in HL-60 cells. Moreover, the treatment of HL-60 cells with etoposide increases the expression of the $\mathrm{HO}-1$ gene and enhances the activity of SOD enzymes, which are also responsible for protecting the cell against ROS (Figures 1 and 2). When HL-60 cells were incubated with another drug used in the treatment of AML, arsenic trioxide, an increase in the glutathione content in the cells was also observed after $24 \mathrm{~h} \mathrm{[57].} \mathrm{Moreover,}$ arsenic trioxide activates NFE2L2 and its downstream target genes HO-1 and NQO1. We showed that both kaempferol and its glycoside derivatives do not affect the level of total glutathione in HL-60 cells (Figure 3). Similar results to those obtained by us have been obtained in studies on Caco- 2 cells. Kaempferol at the concentration of $10 \mu \mathrm{g} / \mathrm{mL}$ did not change the ratio of GSH/GSSG in this cell line [45]. Kaempferol increased the activity of glutathione peroxidase (GSH-Px) and glutathione reductase (GSH-Rx) in the 3T3-L1 cell line but did not increase the level of GSH measured in these cells after $24 \mathrm{~h}$ of incubation [46].

We noticed that kaempferol and derivative P7 increased the level of total glutathione in HL-60 cells treated with etoposide (Figure 3). It is probably caused by the stimulation of enzymes involved in the synthesis of glutathione, such as $\gamma$-glutamate-cysteine ligase (GCL) [33]. Moreover, we did not observe any changes in the cells co-incubated with P2 or P5 and etoposide. In our previous work, we observed that kaempferol and its glycoside derivative P5 did not affect the level of apoptosis induced by $24 \mathrm{~h}$ of incubation with etoposide in HL-60 cells [29]. Additionally, we noticed that derivatives P2 and P7 in the concentration of $50 \mu \mathrm{g} / \mathrm{mL}$ slightly decreased the apoptosis induced by etoposide. This is in line with the results obtained by incubating myeloid leukemia cell lines with topoisomerase II inhibitors (etoposide and doxorubicin) and polyphenols [6]. Emodin, rhein, and cis-stilbene, which did not affect the level of glutathione or lead to its increase, also reduced the level of apoptosis in cells treated with topoisomerase II inhibitors. On the other hand, quercetin and apigenin, in combination with etoposide or doxorubicin, caused a reduction of the glutathione level and the induction of apoptosis. In other studies, curcumin decreased the level of GSH in HL-60 cells treated with etoposide, and it also increased apoptosis [58].

The ability of kaempferol to increase the glutathione level in cells incubated with an anticancer drug has also been reported in normal cells. Research conducted on human umbilical vein endothelial cell HUVECs showed that kaempferol protected these cells from doxorubicin-induced endotheliotoxicity through decreasing ROS generation and maintaining the GSH/GSSG balance [59]. Studies on rats have shown that kaempferol increases the intracellular level of GSH in the hippocampi of both control and $\mathrm{CdCl}_{2}$ (cadmium chloride)-treated animals through the upregulation of NFE2L2 and activation of AMPK [60].

\section{Conclusions}

Kaempferol, due to its antioxidant properties, can directly influence the antioxidant status of cancer cells. Our studies have shown that this polyphenol may influence the oxidative balance indirectly by affecting the expression of antioxidant genes and proteins. We have shown that kaempferol and its glycoside derivatives did not change the expression of the NFE2L2 gene.

Etoposide is an anticancer drug that can induce oxidative stress in cancer cells and lead to their death. We have shown that kaempferol and its glycoside derivatives isolated 
from the aerial parts of Lens culinaris Medik. increase the expression of antioxidant genes, especially the $\mathrm{HO}-1$ gene, SOD activity, and glutathione level in cells treated with etoposide. It seems that the phenolic acid residues attached to the same skeleton are responsible for the differences in the action of kaempferol derivatives, i.e., the caffeic acid residue in P2, the $p$-coumaric acid residue in P5, and the ferulic acid residue in P7. Our results indicated that kaempferol and its derivatives may modulate the activity of etoposide and affect the effectiveness of anticancer therapy based on this drug.

Supplementary Materials: The following supporting information can be downloaded. Table S1: Gene expression changes in HL-60 cells treated with etoposide and kaempferol or its glycoside derivatives.

Author Contributions: Conceptualization, K.W. and M.K.; methodology, M.K., M.J. and J.Ż.; validation, M.K.; investigation, M.K. and M.J.; data curation, K.W.; writing-original draft preparation, M.K.; writing—review and editing, K.W.; visualization, M.K.; supervision, J.Ż., A.S. and K.W. All authors have read and agreed to the published version of the manuscript.

Funding: This research received no external funding.

Institutional Review Board Statement: Not applicable.

Informed Consent Statement: Not applicable.

Data Availability Statement: Not applicable.

Conflicts of Interest: The authors declare no conflict of interest.

\section{References}

1. Liu, Z.; Ren, Z.; Zhang, J.; Chuang, C.C.; Kandaswamy, E.; Zhou, T.; Zuo, L. Role of ROS and Nutritional Antioxidants in Human Diseases. Front. Physiol. 2018, 9, 477. [CrossRef]

2. Kryston, T.B.; Georgiev, A.B.; Pissis, P.; Georgakilas, A.G. Role of oxidative stress and DNA damage in human carcinogenesis. Mutat. Res. 2011, 711, 193-201. [CrossRef]

3. Prasad, S.; Gupta, S.C.; Tyagi, A.K. Reactive oxygen species (ROS) and cancer: Role of antioxidative nutraceuticals. Cancer Lett. 2017, 387, 95-105. [CrossRef]

4. Wu, G.; Fang, Y.Z.; Yang, S.; Lupton, J.R.; Turner, N.D. Glutathione metabolism and its implications for health. J. Nutr. 2004, 134, 489-492. [CrossRef]

5. Estrela, J.M.; Ortega, A.; Mena, S.; Sirerol, J.A.; Obrador, E. Glutathione in metastases: From mechanisms to clinical applications. Crit. Rev. Clin. Lab. Sci. 2016, 53, 253-267. [CrossRef] [PubMed]

6. Mahbub, A.A.; Le Maitre, C.L.; Haywood-Small, S.L.; Cross, N.A.; Jordan-Mahy, N. Glutathione is key to the synergistic enhancement of doxorubicin and etoposide by polyphenols in leukaemia cell lines. Cell Death Dis. 2015, 6, e2028. [CrossRef] [PubMed]

7. Mahbub, A.A.; Le Maitre, C.L.; Haywood-Small, S.L.; Cross, N.A.; Jordan-Mahy, N. Polyphenols act synergistically with doxorubicin and etoposide in leukaemia cell lines. Cell Death Discov. 2015, 1, 15043. [CrossRef]

8. Li, M.; Chiu, J.F.; Kelsen, A.; Lu, S.C.; Fukagawa, N.K. Identification and characterization of an Nrf2-mediated ARE upstream of the rat glutamate cysteine ligase catalytic subunit gene (GCLC). J. Cell. Biochem. 2009, 107, 944-954. [CrossRef] [PubMed]

9. Loboda, A.; Damulewicz, M.; Pyza, E.; Jozkowicz, A.; Dulak, J. Role of Nrf2/HO-1 system in development, oxidative stress response and diseases: An evolutionarily conserved mechanism. Cell. Mol. Life Sci. 2016, 73, 3221-3247. [CrossRef]

10. Ross, D.; Siegel, D. The diverse functionality of NQO1 and its roles in redox control. Redox Biol. 2021, 41, 101950. [CrossRef]

11. Vollrath, V.; Wielandt, A.M.; Iruretagoyena, M.; Chianale, J. Role of Nrf2 in the regulation of the Mrp2 (ABCC2) gene. Biochem. J. 2006, 395, 599-609. [CrossRef]

12. Kobayashi, M.; Yamamoto, M. Molecular mechanisms activating the Nrf2-Keap1 pathway of antioxidant gene regulation. Antioxid. Redox Signal. 2005, 7, 385-394. [CrossRef]

13. Wang, X.J.; Sun, Z.; Villeneuve, N.F.; Zhang, S.; Zhao, F.; Li, Y.; Chen, W.; Yi, X.; Zheng, W.; Wondrak, G.T.; et al. Nrf2 enhances resistance of cancer cells to chemotherapeutic drugs, the dark side of Nrf2. Carcinogenesis 2008, 29, 1235-1243. [CrossRef]

14. Almeida, M.; Soares, M.; Ramalhinho, A.C.; Moutinho, J.F.; Breitenfeld, L.; Pereira, L. The prognostic value of NRF2 in breast cancer patients: A systematic review with meta-analysis. Breast Cancer Res. Treat. 2020, 179, 523-532. [CrossRef]

15. Jeddi, F.; Soozangar, N.; Sadeghi, M.R.; Somi, M.H.; Shirmohamadi, M.; Eftekhar-Sadat, A.T.; Samadi, N. Nrf2 overexpression is associated with P-glycoprotein upregulation in gastric cancer. Biomed. Pharmacother. 2018, 97, 286-292. [CrossRef]

16. Ma, X.; Zhang, J.; Liu, S.; Huang, Y.; Chen, B.; Wang, D. Nrf2 knockdown by shRNA inhibits tumor growth and increases efficacy of chemotherapy in cervical cancer. Cancer Chemother. Pharmacol. 2012, 69, 485-494. [CrossRef]

17. Rushworth, S.A.; Zaitseva, L.; Murray, M.Y.; Shah, N.M.; Bowles, K.M.; MacEwan, D.J. The high Nrf2 expression in human acute myeloid leukemia is driven by NF-KB and underlies its chemo-resistance. Blood 2012, 120, 5188-5198. [CrossRef] 
18. Luo, S.; Lei, K.; Xiang, D.; Ye, K. NQO1 Is Regulated by PTEN in Glioblastoma, Mediating Cell Proliferation and Oxidative Stress. Oxid. Med. Cell. Longev. 2018, 2018, 9146528. [CrossRef] [PubMed]

19. Wu, J.M.; Oraee, A.; Doonan, B.B.; Pinto, J.T.; Hsieh, T.C. Activation of NQO1 in NQO1*2 polymorphic human leukemic HL-60 cells by diet-derived sulforaphane. Exp. Hematol. Oncol. 2015, 5, 27. [CrossRef] [PubMed]

20. Xiao, F.Y.; Jiang, Z.P.; Yuan, F.; Zhou, F.J.; Kuang, W.; Zhou, G.; Chen, X.P.; Liu, R.; Zhou, H.H.; Zhao, X.L.; et al. Down-regulating NQO1 promotes cellular proliferation in K562 cells via elevating DNA synthesis. Life Sci. 2020, 248, 117467. [CrossRef] [PubMed]

21. Anwar, A.; Dehn, D.; Siegel, D.; Kepa, J.K.; Tang, L.J.; Pietenpol, J.A.; Ross, D. Interaction of human NAD(P)H:quinone oxidoreductase 1 (NQO1) with the tumor suppressor protein p53 in cells and cell-free systems. J. Biol. Chem. 2003, 278, 10368-10373. [CrossRef]

22. Che, M.; Wang, R.; Li, X.; Wang, H.Y.; Zheng, X.F.S. Expanding roles of superoxide dismutases in cell regulation and cancer. Drug Discov. Today 2016, 21, 143-149. [CrossRef]

23. Liu, S.; Li, B.; Xu, J.; Hu, S.; Zhan, N.; Wang, H.; Gao, C.; Li, J.; Xu, X. SOD1 Promotes Cell Proliferation and Metastasis in Non-small Cell Lung Cancer via an miR-409-3p/SOD1/SETDB1 Epigenetic Regulatory Feedforward Loop. Front. Cell Dev. Biol. 2020, 8, 213. [CrossRef]

24. Gomez, M.L.; Shah, N.; Kenny, T.C.; Jenkins, E.C., Jr.; Germain, D. SOD1 is essential for oncogene-driven mammary tumor formation but dispensable for normal development and proliferation. Oncogene 2019, 38, 5751-5765. [CrossRef]

25. Li, S.; Fu, L.; Tian, T.; Deng, L.; Li, H.; Xia, W.; Gong, Q. Disrupting SOD1 activity inhibits cell growth and enhances lipid accumulation in nasopharyngeal carcinoma. Cell Commun. Signal. 2018, 16, 28. [CrossRef]

26. Papa, L.; Manfredi, G.; Germain, D. SOD1, an unexpected novel target for cancer therapy. Genes Cancer 2014, 5, 15-21. [CrossRef]

27. Imran, M.; Rauf, A.; Shah, Z.A.; Saeed, F.; Imran, A.; Arshad, M.U.; Ahmad, B.; Bawazeer, S.; Atif, M.; Peters, D.G.; et al. Chemo-preventive and therapeutic effect of the dietary flavonoid kaempferol: A comprehensive review. Phytother. Res. 2019, 33, 263-275. [CrossRef] [PubMed]

28. Kluska, M.; Juszczak, M.; Wysokiński, D.; Żuchowski, J.; Stochmal, A.; Woźniak, K. Kaempferol derivatives isolated from Lens culinaris Medik. reduce DNA damage induced by etoposide in peripheral blood mononuclear cells. Toxicol. Res. 2019, 8, 896-907. [CrossRef] [PubMed]

29. Kluska, M.; Juszczak, M.; Żuchowski, J.; Stochmal, A.; Woźniak, K. Kaempferol and Its Glycoside Derivatives as Modulators of Etoposide Activity in HL-60 Cells. Int. J. Mol. Sci. 2021, 22, 3520. [CrossRef] [PubMed]

30. Żuchowski, J.; Pecio, Ł.; Stochmal, A. Novel Flavonol Glycosides from the Aerial Parts of Lentil (Lens culinaris). Molecules 2014, 19, 18152-18178. [CrossRef]

31. Kumar, A.D.; Bevara, G.B.; Kaja, L.K.; Badana, A.K.; Malla, R.R. Protective effect of 3-O-methyl quercetin and kaempferol from Semecarpus anacardium against $\mathrm{H}_{2} \mathrm{O}_{2}$ induced cytotoxicity in lung and liver cells. BMC Complement. Altern. Med. 2016, 16, 376. [CrossRef]

32. Kim, K.M.; Im, A.R.; Lee, S.; Chae, S. Dual Protective Effects of Flavonoids from Petasites japonicus against UVB-Induced Apoptosis Mediated via HSF-1 Activated Heat Shock Proteins and Nrf2-Activated Heme Oxygenase-1 Pathways. Biol. Pharm. Bull. 2017, 40, 765-773. [CrossRef] [PubMed]

33. Gao, S.S.; Choi, B.M.; Chen, X.Y.; Zhu, R.Z.; Kim, Y.; So, H.; Park, R.; Sung, M.; Kim, B.R. Kaempferol suppresses cisplatin-induced apoptosis via inductions of heme oxygenase-1 and glutamate-cysteine ligase catalytic subunit in HEI-OC1 cell. Pharm. Res. 2010, 27, 235-245. [CrossRef] [PubMed]

34. Wang, Z.; Sun, W.; Sun, X.; Wang, Y.; Zhou, M. Kaempferol ameliorates Cisplatin induced nephrotoxicity by modulating oxidative stress, inflammation and apoptosis via ERK and NF-kB pathways. AMB Express 2020, 10, 58. [CrossRef]

35. Sugahara, M.; Nakanishi, J.; Katsuta, Y. Kaempferol enhanced the intracellular thioredoxin system in normal cultured human keratinocytes. Biosci. Biotechnol. Biochem. 2010, 74, 1701-1703. [CrossRef]

36. Shibata, T.; Ohta, T.; Tong, K.I.; Kokubu, A.; Odogawa, R.; Tsuta, K.; Asamura, H.; Yamamoto, M.; Hirohashi, S. Cancer related mutations in NRF2 impair its recognition by Keap1-Cul3 E3 ligase and promote malignancy. Proc. Natl. Acad. Sci. USA 2008, 105, 13568-13573. [CrossRef]

37. Liu, P.; Ma, D.; Wang, P.; Pan, C.; Fang, Q.; Wang, J. Nrf2 overexpression increases risk of high tumor mutation burden in acute myeloid leukemia by inhibiting MSH2. Cell Death Dis. 2021, 12, 20. [CrossRef] [PubMed]

38. Karathedath, S.; Rajamani, B.M.; MusheerAalam, S.M.; Abraham, A.; Varatharajan, S.; Krishnamurthy, P.; Mathews, V.; Velayudhan, S.R.; Balasubramanian, P. Role of NF-E2 related factor 2 (Nrf2) on chemotherapy resistance in acute myeloid leukemia (AML) and the effect of pharmacological inhibition of NRF2. PLOS ONE 2017, 12, e0177227. [CrossRef]

39. Meyer, S.C.; Levine, R.L. Translational implications of somatic genomics in acute myeloid leukaemia. Lancet Oncol. 2014, 15, e382-e394. [CrossRef]

40. Obrador, E.; Salvador, R.; López-Blanch, R.; Jihad-Jebbar, A.; Alcácer, J.; Benlloch, M.; Pellicer, J.A.; Estrela, J.M. Melanoma in the liver: Oxidative stress and the mechanisms of metastatic cell survival. Sem. Cancer Biol. 2020, 71, 109-121. [CrossRef]

41. Mostafavi-Pour, Z.; Ramezani, F.; Keshavarzi, F.; Samadi, N. The role of quercetin and vitamin C in Nrf2-dependent oxidative stress production in breast cancer cells. Oncol Lett. 2017, 13, 1965-1973. [CrossRef] [PubMed]

42. Fouzder, C.; Mukhuty, A.; Kundu, R. Kaempferol inhibits Nrf2 signalling pathway via downregulation of Nrf2 mRNA and induces apoptosis in NSCLC cells. Arch. Biochem. Biophys. 2021, 697, 108700. [CrossRef] [PubMed] 
43. Son, Y.R.; Choi, E.H.; Kim, G.T.; Park, T.S.; Shim, S.M. Bioefficacy of Graviola leaf extracts in scavenging free radicals and upregulating antioxidant genes. Food Funct. 2016, 7, 861-871. [CrossRef] [PubMed]

44. Chen, Y.L.; Kan, W.M. Down-regulation of superoxide dismutase 1 by PMA is involved in cell fate determination and mediated via protein kinase D2 in myeloid leukemia cells. Biochim. Biophys. Acta 2015, 1853, 2662-2675. [CrossRef]

45. Zhao, C.; Sakaguchi, T.; Fujita, K.; Ito, H.; Nishida, N.; Nagatomo, A.; Tanaka-Azuma, Y.; Katakura, Y. Pomegranate-Derived Polyphenols Reduce Reactive Oxygen Species Production via SIRT3-Mediated SOD2 Activation. Oxid. Med. Cell. Longev. 2016, 2016, 2927131. [CrossRef]

46. Boadi, W.Y.; Amartey, P.K.; Lo, A. Effect of quercetin, genistein and kaempferol on glutathione and glutathione-redox cycle enzymes in 3T3-L1 preadipocytes. Drug Chem. Toxicol. 2016, 39, 239-247. [CrossRef]

47. Budisan, L.; Gulei, D.; Zanoaga, O.M.; Irimie, A.I.; Chira, S.; Braicu, C.; Gherman, C.D.; Berindan-Neagoe, I. Dietary Intervention by Phytochemicals and Their Role in Modulating Coding and Non-Coding Genes in Cancer. Int. J. Mol. Sci. 2017, 18, 1178. [CrossRef]

48. Xu, Y.; Xin, Y.; Diao, Y.; Lu, C.; Fu, J.; Luo, L.; Yin, Z. Synergistic effects of apigenin and paclitaxel on apoptosis of cancer cells. PLOS ONE 2011, 6, e29169. [CrossRef]

49. Cheng, Z.Y.; Chueh, F.S.; Peng, S.F.; Lin, C.H.; Kuo, C.L.; Huang, W.W.; Chen, P.Y.; Way, T.D.; Chung, J.G. Combinational treatment of 5-fluorouracil and casticin induces apoptosis in mouse leukemia WEHI-3 cells in vitro. Environ. Toxicol. 2020, 35, 911-921. [CrossRef]

50. Zhe, N.; Wang, J.; Chen, S.; Lin, X.; Chai, Q.; Zhang, Y.; Zhao, J.; Fang, Q. Heme oxygenase-1 plays a crucial role in chemoresistance in acute myeloid leukemia. Hematology 2015, 20, 384-391. [CrossRef]

51. Lin, X.; Fang, Q.; Chen, S.; Zhe, N.; Chai, Q.; Yu, M.; Zhang, Y.; Wang, Z.; Wang, J. Heme oxygenase-1 suppresses the apoptosis of acute myeloid leukemia cells via the JNK/c-JUN signaling pathway. Leuk. Res. 2015, 39, 544-552. [CrossRef]

52. Miyazaki, T.; Kirino, Y.; Takeno, M.; Samukawa, S.; Hama, M.; Tanaka, M.; Yamaji, S.; Ueda, A.; Tomita, N.; Fujita, H.; et al. Expression of heme oxygenase-1 in human leukemic cells and its regulation by transcriptional repressor Bach1. Cancer Sci. 2010, 101, 1409-1416. [CrossRef] [PubMed]

53. Hong, J.T.; Yen, J.H.; Wang, L.; Lo, Y.H.; Chen, Z.T.; Wu, M.J. Regulation of heme oxygenase-1 expression and MAPK pathways in response to kaempferol and rhamnocitrin in PC12 cells. Toxicol. Appl. Pharmacol. 2009, 237, 59-68. [CrossRef] [PubMed]

54. Chen, Y.; Liang, J.; Liang, X.; Chen, J.; Wang, Y.; Cao, J.; Sun, C.; Ye, J.; Chen, Q. Limonin induces apoptosis of HL-60 cells by inhibiting NQO1 activity. Food Sci. Nutr. 2021, 9, 1860-1869. [CrossRef] [PubMed]

55. Zhang, B.P.; Zhao, J.; Li, S.S.; Yang, L.J.; Zeng, L.L.; Chen, Y.; Fang, J. Mangiferin activates Nrf2-antioxidant response element signaling without reducing the sensitivity to etoposide of human myeloid leukemia cells in vitro. Acta Pharmacol. Sin. 2014, 35, 257-266. [CrossRef] [PubMed]

56. Kagan, V.E.; Kuzmenko, A.I.; Tyurina, Y.Y.; Shvedova, A.A.; Matsura, T.; Yalowich, J.C. Pro-oxidant and antioxidant mechanisms of etoposide in HL-60 cells: Role of myeloperoxidase. Cancer Res. 2001, 61, 7777-7784.

57. Valenzuela, M.; Glorieux, C.; Stockis, J.; Sid, B.; Sandoval, J.M.; Felipe, K.B.; Kviecinski, M.R.; Verrax, J.; Buc Calderon, P. Retinoic acid synergizes ATO-mediated cytotoxicity by precluding Nrf2 activity in AML cells. Br. J. Cancer 2014, 111, 874-882. [CrossRef]

58. Papież, M.A.; Krzyściak, W.; Szade, K.; Bukowska-Straková, K.; Kozakowska, M.; Hajduk, K.; Bystrowska, B.; Dulak, J.; Jozkowicz, A. Curcumin enhances the cytogenotoxic effect of etoposide in leukemia cells through induction of reactive oxygen species. Drug Des. Devel. Ther. 2016, 10, 557-570. [CrossRef]

59. Wu, W.; Yang, B.; Qiao, Y.; Zhou, Q.; He, H.; He, M. Kaempferol protects mitochondria and alleviates damages against endotheliotoxicity induced by doxorubicin. Biomed. Pharmacother. 2020, 126, 110040. [CrossRef]

60. El-Kott, A.F.; Bin-Meferij, M.M.; Eleawa, S.M.; Alshehri, M.M. Kaempferol Protects Against Cadmium Chloride-Induced Memory Loss and Hippocampal Apoptosis by Increased Intracellular Glutathione Stores and Activation of PTEN/AMPK Induced Inhibition of Akt/mTOR Signaling. Neurochem. Res. 2020, 45, 295-309. [CrossRef] 